\title{
THE INHIBITION OF SALMONELLA TYPHI GROWTH BY THE CELL FREE SUPERNATANS OF LACTOBACILLUS ACIDOPHILUS CULTURES
}

\author{
Fanny Rahardja $^{1^{*}}$, M. Nurhalim Shahib², Susy Tjahjani ${ }^{3}$, Dwi Prasetyo ${ }^{4}$ \\ ${ }^{1}$ Department of Microbiology Faculty of Medicine Maranatha Christian University, Bandung, Indonesia \\ ${ }^{2}$ Department of Biochemistry and Molecular Biology Faculty of Medicine Universitas Padjadjaran, Bandung, \\ Indonesia \\ ${ }^{3}$ Department of Parasitology Faculty of Medicine Maranatha Christian University, Bandung, Indonesia \\ ${ }^{4}$ Department of Child Health of Faculty of Medicine Universitas Padjadjaran, Bandung, Indonesia \\ *fanny.rahardja@yahoo.com \\ https://doi.org/10.34302/crpjfst/2019.11.5.1 \\ Article history: \\ Received: \\ 9 March 2019 \\ Accepted: \\ 20 September 2019 \\ Keywords: \\ Antimicrobial potency; \\ Cell-free supernatant; \\ Ciprofloxacin; \\ Lactobacillus acidophilus; \\ Salmonella typhi

\section{ABSTRACT} \\ Fever caused by Salmonella enterica serovar typhi is presently a major \\ public health concern in developing countries. The extensive use of \\ recommended antibiotics such as ciprofloxacin has resulted in the reduction \\ of its efficacy in the elimination of Salmonella typhi. Lactobacillus \\ acidophilus secretes antimicrobial compounds against pathogenic bacteria. \\ The aim of this study was to evaluate the antibacterial activity of cell-free \\ supernatants (CFS) of Lactobacillus acidophilus against the growth of \\ Salmonella typhi. The efficacy of organic acids and other compounds from \\ L. acidophilus CFS was tested against Salmonella typhi using macro dilution \\ test and time-kill study. The results were reported descriptively. Four-fold \\ dilutions of organic acids and two-fold dilutions of other compounds from \\ $L$. acidophilus CFS were found to inhibit the growth of $S$. typhi. It was \\ observed that $L$. acidophilus CFS can completely inhibit the growth of $S$. \\ typhi. The CFS of Lactobacillus acidophilus especially due to its organic \\ acid content showed an inhibitory effect against S. typhi growth.
}

\section{Introduction}

Typhoid fever is an ongoing health concern over the world, especially in developing countries (Zaki, 2011). Typhoid fever is an acute infectious disease caused by Salmonella enterica serovar typhi (Zaki, 2011). S. typhi is a gram-negative, rod-shaped, facultatively anaerobic, and motile bacterium that is pathogenic to humans. Transmission of these bacteria occurs through the ingestion of food and water contaminated with infected human waste or via carriers of the disease. An estimated 17.8 million (6.9-48.4 million) new cases of typhoid fever have been reported per year. The Central, South and Southeast Asia have a high incidence of typhoid (Garcia-Fernandez et al., 2014;
Garcia et al., 2015; Warren, et al., 2017). The endemic nature of typhoid in developing countries is closely associated with poor hygiene and sanitation (Eng, et al., 2015). Serious complications that could occur in typhoid fever are intestinal bleeding, perforation, and even death (Eng, et al., 2015).

The first line of antibiotics used to eliminate $S$. typhi includes chloramphenicol, ampicillin, and cotrimoxazole. However, some strains of $S$. typhi are presently resistant to these antibiotics (Zaki, 2011). Ciprofloxacin is now used to treat infections caused by multidrug resistant strains. However, various studies in Peru, Italy, Africa, and Southeast Asia have also reported that the antimicrobial activity of ciprofloxacin in 
inhibition of multidrug-resistant strains has also declined, probably due to its extensive use (Garcia-Fernandez et al., 2014; Garcia et al., 2015; Schellack, 2018). In Cambodia, 90\% of the $S$. typhi isolates have shown a decrease in susceptibility to ciprofloxacin and azithromycin (Vlieghe et al.,2012). This has resulted in an urgent situation requiring the development of novel therapeutic strategies to inhibit the occurrence of antibiotic resistance in S. typhi

Probiotics are microorganisms that have potential health benefits to human, when ingested in an appropriate quantity (BermudezBrito et al.,2012). Lactobacillus spp. and Bifidobacterium spp. have been extensively studied, as they are the predominant groups of the human gastrointestinal microflora (Bermudez-Brito et al., 2012). The research on probiotics under in vitro and in vivo conditions has concluded that probiotics can improve the response to inflammation due to microbial infection, through various mechanism of action (Bermudez-Brito et al., 2012). Probiotics have been known to enhance the first line of defense by limiting the attachment and proliferation of microbial pathogens (Bermudez-Brito et al., 2012). Certain probiotics produce antimicrobial compounds and modulate the immune system, though the exact mechanism of action has not yet been fully understood (Bermudez-Brito et al., 2012). Lactic acid bacteria form a group of probiotics that are able to produce lactic acid. Lactobacillus acidophilus is classified as a lactic acid bacterium. L. acidophilus is a grampositive, catalase-negative rod that produces lactic acid through carbohydrate fermentation (Bull et al., 2013). L. acidophilus can be isolated as a normal flora from various parts of the human body, such as the buccal cavity, intestinal tract, colon and vagina. L. acidophilus has potential benefits for human health and exerts therapeutic effects. It is known that $L$. acidophilus produces antibacterial substances, maintains barrier function, ameliorates inflammation due to infection by Helicobacter sp., and offers immunomodulation (Bull et al., 2013; Coconnier et al., 1998; Sengupta et al., 2013). The aim of this study was to evaluate the inhibitory potential of cell free supernatants of L. acidophilus on the growth of S. typhi.

\section{Materials and methods}

\subsection{Microorganisms}

The strain of Salmonella typhi used in this study was isolated from a hospitalized patient that was diagnosed with typhoid fever at the Immanuel Hospital, Bandung, Indonesia. The isolate was identified using standard bacteriological methods. The purified strain was grown on Trypticase Soya Agar (Oxoid) and sub cultured in Trypticase Soya Broth (Oxoid) at 37 ${ }^{\circ} \mathrm{C}$ for $24 \mathrm{~h}$. Before the use in the experiment, the culture was inoculated in Tryptic Soya Agar at $37{ }^{\circ} \mathrm{C}$ for 24 hours. Bacterial density was measured by suspending $5-10$ colonies in $0.9 \%$ $\mathrm{NaCl}$ (Sigma-Aldrich-Merck) to the equivalent of the $0.5 \mathrm{McF}$ arland standard.

Lactobacillus acidophilus ATCC 4356 was purchased from Microbiologics ${ }^{\mathrm{TM}}$ Fisher scientific. The strain was identified using gram staining and biochemical tests (Branch,2015). The culture was stored in de man Rogosa Sharpe slant agar (Oxoid) at $4-8^{\circ} \mathrm{C}$ and subcultured in MRS broth at $37^{\circ} \mathrm{C}$ for $24 \mathrm{~h}$ before the use in the experiment.

\subsection{Preparation of Organic Acid Cell free supernatant (OACFS)}

L. acidophilus ATCC 4356 was anaerobically cultured in de man Rogosa Sharpe broth at $37^{\circ} \mathrm{C}$ for $24 \mathrm{~h}$. CFS was obtained by centrifuging the bacterial culture at $6,000 \mathrm{rpm}$ and $4{ }^{\circ} \mathrm{C}$ for 15 minutes (Eppendorf, Centrifuge $5424 \mathrm{R}$, Germany). The supernatant was filtersterilized using a 0.2-micron filter (Minisart, Sartorius Stedim biotech). The filtrate was then placed in UV light Biosafety Cabinet (Telstar Bio II Advance) for 40 minutes.

\subsection{Preparation of Other Compunds Cell Free Supernatant (OCCFS) \\ CFS from the L. acidophilus was obtained as described above and was neutralized to $\mathrm{pH} 7.0$ using $2 \mathrm{~N} \mathrm{NaOH}$ (Sigma-Aldrich-Merck) and}


sterilized using 0.2-micron filter (Minisart, Sartorius Stedim biotech) (Kaur, 2015).

\subsection{Determination of Minimal Inhibitory Concentration (MIC).}

The MIC values were determined by the tube macro dilution technique. Two-fold serial dilutions of ciprofloxacin, OACFS, and OCCFS (crude bacteriocin) were prepared volumetrically in Mueller-Hinton (MH) broth (Oxoid). The bacterial suspension was added to the broth containing the dilutions and incubated at $37^{\circ} \mathrm{C}$ for $24 \mathrm{~h}$. MIC was defined as the lowest concentration of the compound that showed no visible growth of $S$. typhi, demonstrated by the absence of turbidity in the broth.

\subsection{Time-kill Study}

The Time-kill curves of $S$. typhi were constructed by evaluating the reduction in the number of colony forming units $(\mathrm{CFU}) / \mathrm{mL}$ following exposure to $\mathrm{CFS}$ in $\mathrm{MH}$ broth at $37^{\circ} \mathrm{C}$ for $48 \mathrm{~h}$. An inoculum of $10^{8} \mathrm{CFU} / \mathrm{mL}$ of $S$. typhi was used for this test. The samples were collected from the culture of the test bacteria at time intervals of $0,4,8,12,24,28,32,36$ and 48 $\mathrm{h}$, diluted serially, and cultured in triplicate in Plate Count Agar at $37{ }^{\circ} \mathrm{C}$ for $24 \mathrm{~h}$ (Del, 2017).
The numbers of viable cells were counted as $\mathrm{CFU} / \mathrm{mL}$.

\section{Results and discussions}

The strain of L. acidophilus used in this study was tested for its ability to produce lactic acid and other compounds which inhibited the growth of $S$. typhi. Upon inoculating $L$. acidophilus on de man Rogosa Sharpe Agar (MRSA) plates containing $\mathrm{CaCO}_{3}$, zones of inhibition were obtained around the colonies, which indicated that L. acidophilus could produce lactic acid. OACFS and OCCFS were prepared from the culture of L. acidophilus and their antimicrobial activity was evaluated. The $\mathrm{pH}$ of OACFS was 4.1. The antimicrobial activity of CFS was compared with the recommended antibiotics.

Two-fold serial dilutions of ciprofloxacin, OACFS and OCCFS were prepared for the broth macro dilution method. The MIC was $0.2 \mu \mathrm{g} / \mathrm{mL}$ of ciprofloxacin (Table 1), 4-fold dilution of OACFS, and 2-fold dilution of OCCFS (Table $2)$. For the time-kill study, normal S. typhi growth curves were compared with that in the OACFS, OCCFS, and ciprofloxacin at their respective MIC (figure 1).

Table 1. Minimal Inhibitory Concentration (MIC) of ciprofloxacin

\begin{tabular}{|c|c|c|c|c|c|c|c|c|c|c|}
\hline \multirow{4}{*}{ Ciprofloxacin } & \multicolumn{10}{|c|}{ Concentration $(\mu \mathrm{g} / \mathrm{ml})$} \\
\cline { 2 - 9 } & 25 & 12.5 & 6.25 & 3.12 & 1.56 & 0.78 & 0.39 & 0.2 & 0.1 & 0.05 \\
\cline { 2 - 9 } & $\begin{array}{c}\text { No } \\
\text { growth }\end{array}$ & $\begin{array}{c}\text { No } \\
\text { growth }\end{array}$ & $\begin{array}{c}\text { No } \\
\text { growth }\end{array}$ & $\begin{array}{c}\text { No } \\
\text { growth }\end{array}$ & $\begin{array}{c}\text { No } \\
\text { growth }\end{array}$ & $\begin{array}{c}\text { No } \\
\text { growth }\end{array}$ & $\begin{array}{c}\text { No } \\
\text { growth }\end{array}$ & $\begin{array}{c}\text { No } \\
\text { growth }\end{array}$ & Growth & Growth \\
\hline
\end{tabular}

Table 2. Minimal Inhibitory Concentration (MIC) of organic acid cell-free supernatant (OACFS) and other compounds cell-free supernatant (OCCFS)

\begin{tabular}{|c|c|c|c|c|c|}
\hline \multirow{2}{*}{} & \multicolumn{4}{|c|}{ Concentration of CFS dilution } \\
\cline { 2 - 6 } & 2-fold & 4-fold & 8-fold & 16-fold & 32-fold \\
\hline Organic acid & No growth & No growth & Growth & Growth & Growth \\
\hline Other Compounds & No growth & Growth & Growth & Growth & Growth \\
\hline
\end{tabular}




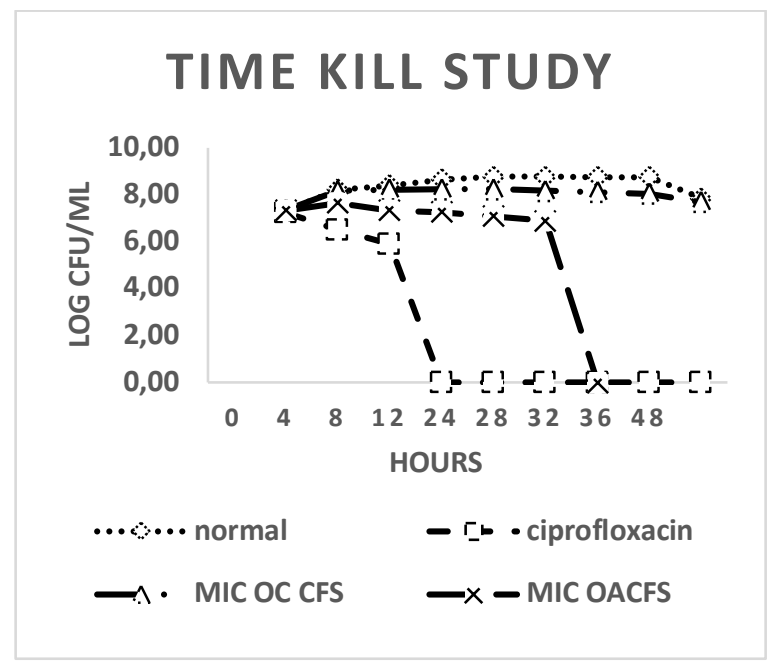

Figure 1. The comparison of $S$. typhi growth in the presnce of ciprofloxacin, OACFS, and OCCFS.

Lactobacillus spp. are probiotics that can be found in the gastrointestinal tract. $L$. acidophilus is used extensively in research to develop probiotics as a complementary therapy. In this study, OACFS showed the bactericidal effect after 36 hours of incubation. The possible mechanism of the bactericidal effect of these organic acids especially acetic acid and lactic acid involves their ability to enter the bacterial cell and disrupt cytoplasm (Bermudez-Brito et al., 2012). S. typhi is an acid-sensitive bacterium. Organic acids with low $\mathrm{pH}$ can directly lead to the death of S. typhi. The bactericidal effect of organic acids appears to accelerate the typhoid fever recovery process. In this study, the antimicrobial activity of OCCFS appears to be limited against $S$. typhi. The inhibition of the OCCFS may be attributed to the presence of bacteriocin and other peptides (having antimicrobial activity) that are produced by the lactic acid bacteria. Bacteriocin is an antimicrobial substance that could disrupt the bacterial cell membrane permeability, which may cause perforation in the bacterial cell wall (Gogineni et al., 2013). Further studies by using other isolation OCCFS method is needed to evaluate its in vitro effect in inhibition the growth of $S$. typhi.

Ciprofloxacin is a quinolone antibiotic, which acts by inhibiting the bacterial DNA gyrase and topoisomerase IV during bacterial replication (Abde-daim et al., 2013). The isolate studied in this work was sensitive to ciprofloxacin based on recent CLSI MIC recommendation (sensitive: $\leq 1 \mu \mathrm{g} / \mathrm{mL}$, Intermediate: $2 \mu \mathrm{g} / \mathrm{mL}$, Resistant $\geq 4 \mu \mathrm{g} / \mathrm{mL}$ (Scellack et al., 2018). However, this strain required a higher concentration of ciprofloxacin to show growth inhibition.

The decrease in susceptibility to ciprofloxacin is defined when an isolate of Salmonella showed an MIC of 0.12-2 $\mu \mathrm{g} / \mathrm{mL}$ (Inical et al., 2011). Further studies are required to ascertain the decrease in susceptibility of this strain to ciprofloxacin.

\section{Conclusions}

Our study found that the cell-free supernatants of L. acidophilus especially those containing organic acids have an inhibitory effect in the growth curves of $S$. typhi.It appears that L. acidophilus exerts an antimicrobial effect on $S$. typhi and it may offer a promising therapeutic approach for the elimination of $S$. typhi

\section{References}

Abdel-daim, N. Hassouna, M. Hafez, Ashor,M.S.A and M. M. Aboulwafa (2013). Antagonistic Activity of Lactobacillus Isolates against Salmonella typhi In Vitro.Biomed Research International 1-12,doi.org / 10.1155/ 2013 / 680605.

Bermudez-Brito,M., Plaza-Diaz,J.,Muñozquezada, S.,Gomez-Llorente,C.,Gil,A. (2012). Probiotic Mechanisms of Action. Annals of Nutrition \& Metabolism, 61,160-174.

Bull, M., Plummer, S., Marchesi, J. Mahenthiralingam, E..(2013). The life history of Lactobacillus acidophilus as a probiotic: A tale of revisionary 
taxonomy, misidentification and commercial success. FEMS Microbiol. Lett, 77-87.

Coconnier, M., Lievin, V., Hemery, E., Servin, A. L. (1998). Antagonistic Activity against Helicobacter Infection In Vitro and In Vivo by the Human Lactobacillus acidophilus Strain LB. Applied and Environmental Microbiology , 64, 11, 4573-80.

Del, L. (2017).Antibacterial Activities and Possible Modes of Action of Acacia nilotica (L.) against Multidrug-Resistant Escherichia coli and Salmonella. Molecules, 1-2

Eng, S., Pusparajah, P., Mutalib, N. A., Ser, H., Chan, K., Lee, L. (2015). Salmonella: A review on pathogenesis, epidemiology and antibiotic resistance. Frontier in Life Science, 8,3, 284-293.

García, C., Lejon, V., Horna, G., Astocondor, L., Vanhoof, R., Bertrand, S. (2014). Intermediate Susceptibility to Ciprofloxacin among Salmonella enterica Serovar Typhi Isolates in Lima, Peru. Journal of Clinical Microbiology. 52,3, 968-970.

García-fernández, S.A., Gallina, S., Owczarek, S., Dionisi, A. M. (2015) Emergence of Ciprofloxacin-Resistant Salmonella enterica Serovar typhi in Italy. PLoS ONE,1-2

Hassing, R., Menezes, G. A., Van Pelt, W., Petit, P. L., Van Genderen, P. J., Goessens, W. H. F. (2011). Analysis of mechanisms involved in reduced susceptibility to ciprofloxacin in Salmonella enterica serotypes Typhi and Paratyphi A isolates from travellers to Southeast Asia. International. Journal of Antimicrobial Agents,37,3, 240-3.

Inical, C.L., Tice,P. (2012). In Vitro Susceptibility Testing of Fluoroquinolone Activity Against Salmonella: Recent Changes to CLSI
Standards. Clinical Practice. 55, 11071113.

Kaur, S., Kaur, H. P..( 2015). Evaluation of Antibacterial Activity of Bacteriocin Produced from Lactobacillus sp . Isolated from Rhizosphere Soil.International Journal of Pure \& Applied Bioscience, 3, 3, 136-142.

Schellack , N., Bronkhorst,E., Maluleka,C., Hunt.L.,Srinivas,P., Babarinde,O.(2018). Infection : a report of two cases in South Africa Fluoroquinolone-resistant Salmonella typhi infection: a report of two cases in South Africa," Southern African Journal of Infectious Disease,vol. 33, no. 2, 54-6.

Sengupta, R., Altermann, E., Anderson, R. C., McNabb, W. C.,Moughan, P. J., Roy, N. C. (2013). The role of cell surface architecture of lactobacilli in hostmicrobe interactions in the gastrointestinal tract. Mediators of Inflammation, 1,7-9

Vlieghe, E. R., et al. (2012). Azithromycin and Ciprofloxacin Resistance in Salmonella Bloodstream Infections in Cambodian Adults. Plos Negleted of Tropical Disease, 6, 12.

Warren, J. L., Crawford, F. W., Weinberger, D. M. (2017). The burden of typhoid fever in low- and middle-income countries: A meta-regression approach. Plos Negleted of Tropical Disease, 11(2), 1-21.

Zaki, S. A., Karande, S..(2011).Review article Multidrug-resistant typhoid fever : a review. Journal Infect Dev Ctries, 5(5):324-27.

\section{Acknowledgment}

The authors thank Dr. Wahyu Widowati from Biomolecular and Biomedical Research Center for laboratory support. The authors also thank to Ms Shinta Asarina and $\mathrm{Mr}$ Ubaydillah Munshy for technical assistance. 